\title{
Anticoagulant strategies for the patient with chronic kidney disease
}

\author{
Authors: Jonathan P Law, ${ }^{A}$ Luke Pickup, ${ }^{B}$ Jonathan N Townend ${ }^{C}$ and Charles J Ferro ${ }^{D}$
}

\begin{abstract}
Chronic kidney disease (CKD) is a global health problem affecting up to $14 \%$ of the adult population in developed countries. On the basis of current guidelines, patients with CKD will often fulfil criteria for both short-term and long-term anticoagulation. Paradoxically, patients with CKD are not only at a higher risk of thrombosis, they are also at increased risk of bleeding. Furthermore, the pharmacokinetics and pharmacodynamics of many anticoagulant therapies are significantly affected by renal dysfunction. In addition, patients with advanced CKD are often systematically excluded from major clinical trials. As such, the decision on whether to anticoagulate or not, and if so with what agent, poses significant challenges. A solid understanding of the condition in question and the available treatments is required to make an informed judgement call. An in-depth appreciation of the advantages and disadvantages of the currently available anticoagulants is a key element in the decision-making process.
\end{abstract}

DOI: 10.7861/clinmed.2019-0445

\section{Introduction}

Chronic kidney disease (CKD) is a global health problem affecting up to $14 \%$ of the adult population in developed countries. ${ }^{1}$ The risk for venous thromboembolism (VTE) is two to three times greater in patients with CKD and end-stage kidney disease (ESKD), respectively, than the general population. ${ }^{2}$ The risk for atrial fibrillation (AF) is also 10 to 20 times greater in patients with CKD and ESKD. ${ }^{3}$ Furthermore, the harm caused by these conditions is greater in patients with CKD/ESKD. For example, patients with both CKD and AF have a higher stroke

Authors: ${ }^{A}$ renal specialist registrar and British Heart Foundation clinical research fellow, University of Birmingham, Birmingham, UK and University Hospitals Birmingham NHS Foundation Trust, Birmingham, UK; ${ }^{\mathrm{B}}$ cardiology specialist registrar and British Heart Foundation clinical research fellow, University of Birmingham, Birmingham, UK and University Hospitals Birmingham NHS Foundation Trust, Birmingham, UK; ${ }^{C}$ consultant cardiologist and professor of cardiology, University of Birmingham, Birmingham, UK and University Hospitals Birmingham NHS Foundation Trust, Birmingham, UK; ${ }^{\text {D }}$ consultant nephrologist and professor of renal medicine, University of Birmingham, Birmingham, UK and University Hospitals Birmingham NHS Foundation Trust, Birmingham, UK risk and mortality than patients with either isolated AF or CKD. ${ }^{3}$ Patients with CKD/ESKD have an increased prevalence of cardiovascular risk factors, including diabetes mellitus and hypertension, and an increased risk of cardiovascular conditions including angina, myocardial infarction and heart failure. ${ }^{1}$ On the basis of current guidelines, patients with CKD/ESKD will often fulfil criteria for both short-term and long-term anticoagulation as emergency treatment for VTE or acute coronary syndromes (ACS), VTE thromboprophylaxis during hospitalisation, and longterm anticoagulation for AF.

Paradoxically, patients with CKD, and especially those with ESKD are not only at a higher risk of thrombosis, they are also at increased risk of bleeding even without anticoagulant treatment. ${ }^{3-7}$ The increased bleeding risks of anticoagulants are exacerbated further by the significant effects of CKD on the pharmacokinetics and pharmacodynamics of many anticoagulant drugs. ${ }^{5,8}$ As such, managing both short-term and long-term anticoagulation in patients with CKD/ESKD poses significant challenges.

\section{Key points}

Chronic kidney disease is a highly prevalent condition and patients with this condition will often fulfil the criteria specified in several current guidelines for both short- and long-term anticoagulation.

Patients with chronic kidney disease are not only at higher risk of thrombosis, they are also at increased risk of bleeding.

The pharmacokinetics and pharmacodynamics of many anticoagulant therapies are significantly affected by renal dysfunction.

Patients with chronic kidney disease have been routinely excluded from major clinical trials.

An in-depth knowledge of the indication for and advantages of anticoagulation, an appreciation of the risks associated with anticoagulation, and an awareness of the advantages and disadvantages of the currently available anticoagulants are key factors in the decision-making process.

KEYWORDS: Chronic kidney disease, venous thromboembolism, anticoagulation, haemorrhage, heparin 
The paradox of increased hypercoagulability and increased haemorrhagic risk with decreasing renal function

The mechanisms which lead to hypercoagulability in patients with CKD/ ESRD are multiple and the underlying pathophysiology is essentially attributable to all three components of Virchow's triad: endothelial injury/dysfunction, venous stasis and abnormal blood constituents. ${ }^{4,5}$ In addition to the conventional thrombotic sites, arteriovenous fistulae and grafts, as well as dialysis lines necessary for haemodialysis, are also prone to thrombosis. Central venous stenosis and thrombosis are associated with prior and/or repeated central venous catheterisation resulting in excessive vessel wall shear stress, endothelial damage, and neointimal hyperplasia. ${ }^{9}$ Some patients with CKD may also have a primary renal or otherwise significant inherited or acquired disease, perhaps best exemplified by the nephrotic syndrome..$^{10}$ Any form of nephrotic syndrome is associated with an eight-fold increased risk of VTE compared with the general population. ${ }^{10}$ Glomerular loss of antithrombin III and protein because of a primary or secondary glomerular basement membrane abnormality and podocytopathy, leads to increased hepatic synthesis of fibrinogen, factor $\mathrm{V}$, factor VII and factor VIII. ${ }^{10}$ This is also accompanied by thrombocytosis and increased platelet activation, resulting in an imbalance of the coagulation system leaning towards hypercoagulopathy.

The presence of CKD/ESKD is associated with an increased haemorrhage risk. ${ }^{4,6,11}$ The pathophysiological mechanisms of the increased bleeding risk associated with uraemia are diverse and include increased vascular prostaglandin $\mathrm{I}_{2}$, decreased von Willebrand factor, hyperparathyroidism, chronic inflammation, decreased nitric oxide bioavailability, anaemia and platelet abnormalities leading to abnormal adhesion and aggregation. ${ }^{3-6}$ Even when coagulation has occurred, the structure of thrombus in CKD is highly abnormal resulting in less effective haemostasis. ${ }^{12}$

Another major contributor to haemorrhage risk is concomitant drug therapy. Antiplatelet agents, such as aspirin and clopidogrel, usage is prevalent in CKD/ESKD patients in line with the common occurrence of coexisting vascular disease. ${ }^{1,6}$ Furthermore, patients with ESKD on haemodialysis are intermittently systemically anticoagulated at least three times a week to minimise clotting of haemodialysis circuits. ${ }^{13}$

\section{When and how to anticoagulate}

The delicate balance between thrombotic and haemorrhagic risk in patients with CKD/ESKD, the altered pharmacodynamics and pharmacokinetics of anticoagulant drugs associated with renal impairment as well as multiple other variables in specific sub-groups, all contribute to making the decision on whether to anticoagulate or not quite challenging. The decision-making process is further complicated by lack of direct evidence of benefit or harm, largely because patients with advanced CKD and ESKD have usually been systematically excluded from major randomised controlled trials. ${ }^{14}$ Furthermore, there are no thromboembolic or bleeding risk scores that accurately define risk in patients with advanced CKD/ESKD. ${ }^{15}$

Discussing all the conditions that might require anticoagulation and the pros and cons of doing so, together with the available supporting evidence in patients with different levels of renal function is clearly beyond the scope of this article, as are anticoagulation strategies during haemodialysis. ${ }^{13}$ However, once the decision is made to start anticoagulation, choosing the correct anticoagulant requires consideration of the indication, route of administration, availability of reversal agents, potential interactions with concurrent medications, dependence on renal function for elimination and therefore predicted renal function trajectory, all of which will inform the optimal starting dosage and monitoring intervals.

\section{Anticoagulants}

The currently available options for anticoagulation break down into two groups: the parenteral forms including unfractionated heparin (UFH), low-molecular-weight heparins (LMWH) and direct thrombin inhibitors, and the oral forms including vitamin $\mathrm{K}$ antagonists and the direct oral anticoagulants (DOACs).

\section{Parenteral anticoagulants}

The currently available parenteral anticoagulants in the UK, together with their pharmacology and dose changes, recommended in patients with CKD/ESKD are summarised in Table 1.

\section{Unfractionated heparin}

Unfractionated heparin benefits from a rapid onset of action, a short half-life and easy reversibility with protamine. These are ideal properties for patients who are at a high risk of bleeding or require bridging anticoagulation for invasive procedures. Frequent subcutaneous administration or continuous intravenous infusion is required and regular monitoring of activated partial thromboplastin time or activated clotting time is mandated due to unpredictable bioavailability. ${ }^{5}$ Initial dosing of UFH is generally the same in CKD as in subjects with normal renal function, maintenance therapy is then adjusted according to monitoring results. A $30 \%$ reduction in dose may be needed in those with severe CKD (Table 1). ${ }^{5,16}$

\section{Low-molecular-weight heparins}

Enoxaparin, dalteparin and tinzaparin have largely replaced UFHs in clinical practice due to ease of administration and predictable pharmacokinetics requiring once or twice daily dosing. ${ }^{5}$ They are primarily inhibitors of factor Xa through antithrombin with variable effects on other coagulation factors. No monitoring is generally required, although monitoring anti-Xa levels may be required in prolonged use. Dose adjustments are required in moderate-severe CKD (Table 1).

\section{Heparin-induced thrombocytopenia}

Heparin-induced thrombocytopenia (HIT) is a life-threatening, prothrombotic state in which antibodies to heparin-platelet complexes lead to platelet activation. ${ }^{17}$ Although the immune reaction is common (8-50\%), the clinical complications of thrombocytopenia and thrombosis are rare $(0.2-3 \%)$ and are not increased in CKD. ${ }^{17}$ Treatment essentially revolves around avoidance of further heparin-based therapies and continued anticoagulation.

\section{Fondaparinux}

Fondaparinux is a synthetic pentasaccharide $\mathrm{LMWH} .{ }^{17}$ It does not cross-react with HIT antibodies. ${ }^{17}$ It is renally eliminated and dose reductions are required in patients with moderate CKD (Table 1). It is not recommended in advanced CKD because of reports of high risks of major bleeding. 5,17

\section{Direct thrombin inhibitors}

Argatroban, bivalrudin and lepirudin are inhibitors of thrombin often used in the treatment of HIT, although argatroban is the 
Table 1. Pharmacological targets, main clearance pathways and UK licensed indications of parenteral anticoagulants

\begin{tabular}{|c|c|c|c|c|}
\hline Anticoagulant & Target & $\begin{array}{l}\text { Main clearance } \\
\text { pathway }\end{array}$ & $\begin{array}{l}\text { UK } \\
\text { indications }\end{array}$ & Adjustment for renal impairment \\
\hline \multirow{4}{*}{$\begin{array}{l}\text { Unfractionated } \\
\text { heparin } \\
\text { (SC and IV) }\end{array}$} & \multirow{4}{*}{$\begin{array}{l}\text { Inhibition of thrombin and } \\
\text { factor } X \text { through AT }\end{array}$} & \multirow{4}{*}{$\begin{array}{l}\text { Reticuloendothelial } \\
\text { system }\end{array}$} & VTE & No dose adjustment for ACS \\
\hline & & & ACS & Other indications reduce dose by $33 \%$ if \\
\hline & & & APAO & $\mathrm{CrCl}<15 \mathrm{~mL} / \mathrm{min}$ \\
\hline & & & & Subsequent APTT adjusted dosing \\
\hline \multirow{4}{*}{$\begin{array}{l}\text { Enoxaparin } \\
\text { (SC only) }\end{array}$} & \multirow{4}{*}{$\begin{array}{l}\text { Inhibitor of factor Xa, IIa } \\
\text { and thrombin through AT }\end{array}$} & \multirow[t]{4}{*}{ Renal } & \multirow[t]{4}{*}{ VTE } & No dose adjustment for PE \\
\hline & & & & Reduce dose by $50 \%$ if $\mathrm{CrCl}<30 \mathrm{~mL} / \mathrm{min}$ \\
\hline & & & & Not recommended if $\mathrm{CrCL}<15 \mathrm{~mL} / \mathrm{min}$ \\
\hline & & & & $\begin{array}{l}\text { Consider anti-Xa adjusted dosing for } \\
\text { prolonged treatment (anti-Xa:IIa ratio 3.9) }\end{array}$ \\
\hline \multirow{2}{*}{$\begin{array}{l}\text { Tinzaparin } \\
\text { (SC only) }\end{array}$} & \multirow{2}{*}{$\begin{array}{l}\text { Inhibitor of factor } \mathrm{Xa} \text { and } \\
\text { other coagulation factors } \\
\text { through AT }\end{array}$} & \multirow[t]{2}{*}{ Renal } & \multirow[t]{2}{*}{ VTE } & Not needed \\
\hline & & & & $\begin{array}{l}\text { Consider anti-Xa adjusted dosing for } \\
\text { prolonged treatment (anti-Xa:Ila ratio 2.8) }\end{array}$ \\
\hline \multirow{2}{*}{$\begin{array}{l}\text { Dalteparin } \\
\text { (SC only) }\end{array}$} & \multirow{2}{*}{$\begin{array}{l}\text { Inhibitor of factor Xa, } \\
\text { thrombin through AT }\end{array}$} & \multirow[t]{2}{*}{ Renal } & ACS & \multirow[t]{2}{*}{ Not needed } \\
\hline & & & VTE & \\
\hline \multirow{3}{*}{$\begin{array}{l}\text { Fondaparinux } \\
\text { (SC only) }\end{array}$} & \multirow{3}{*}{$\begin{array}{l}\text { Selective inhibitor of factor } \\
\text { Xa through AT }\end{array}$} & \multirow[t]{3}{*}{ Renal } & VTE & Reduce dose by $50 \%$ if $\mathrm{CrCl} 30-50 \mathrm{~mL} / \mathrm{min}$ \\
\hline & & & \multirow[t]{2}{*}{ ACS } & VTE: do not use if $\mathrm{CrCl}<30 \mathrm{~mL} / \mathrm{min}$ \\
\hline & & & & ACS: do not use if $\mathrm{CrCl}<20 \mathrm{~mL} / \mathrm{min}$ \\
\hline Argatroban (IV only) & Direct thrombin inhibitor & Faeces & HIT & $\begin{array}{l}\text { Not needed (renal clearance }<15 \% \text { ); APTT } \\
\text { monitoring required }\end{array}$ \\
\hline Bivalirudin (IV only) & Direct thrombin inhibitor & Renal & ACS & Do not use if $\mathrm{CrCL}<30 \mathrm{~mL} / \mathrm{min}$ \\
\hline $\begin{array}{l}\text { Danaparoid } \\
\text { (SC and IV) }\end{array}$ & $\begin{array}{l}\text { Selective inhibitor of factor } \\
\text { Xa through AT }\end{array}$ & Renal & HIT & $\begin{array}{l}\text { Avoid if } \mathrm{CrCL}<30 \mathrm{~mL} / \mathrm{min} \text { or in dialysis } \\
\text { patients unless no alternative to manage } \\
\text { HIT available }\end{array}$ \\
\hline
\end{tabular}

The dose adjustments suggested are for guidance only and the reader is directed to local protocols and formularies for definitive dosing. ACS = acute coronary syndrome; $\mathrm{APAO}=$ acute arterial peripheral occlusion; $\mathrm{APTT}=$ activated partial thromboplastin time; $\mathrm{AT}=$ antithrombin; $\mathrm{CrCl}=\mathrm{creatinine}$ clearance rate; $\mathrm{HIT}=$ heparin induced thrombocytopenia; IV = intravenous; PE = pulmonary embolism; SC = subcutaneous; VTE = venous thromboembolism.

only one licensed in the UK for this indication. ${ }^{17,18}$ Argatroban is metabolised in the liver and no dose-modification required in CKD. Both bivalirudin and lepirudin are significantly cleared by the kidneys and their use is not recommended in advanced CKD (Table 1).

\section{Danaparoid}

Danaparoid is a mixture of naturally occurring glycosaminoglycans with anti-Xa activity. ${ }^{19}$ It is mainly renally cleared but has been used with success in CKD when HIT has been diagnosed and no other anticoagulant options are suitable or available. ${ }^{5,17}$

\section{Oral anticoagulants}

The currently available oral anticoagulants in the UK, warfarin and the DOACs, together with their indications, pharmacology and dose changes in patients with CKD/ESRD are summarised in Table 2.

\section{Warfarin}

Warfarin remains a popular choice for many patients with CKD, especially for those with ESKD, despite having a narrow therapeutic range and a susceptibility to multiple drug and food interactions. Patients with CKD often require lower daily doses to achieve therapeutic levels due to downregulation of CYP450. ${ }^{8}$ Although there is considerable evidence that anticoagulation with warfarin may not be associated with benefit in patients with ESKD in conditions such as AF, this may be largely mitigated if the time within the therapeutic ratio can be maintained above $70 \%{ }^{3}$ Long-term warfarin use is, however, associated with accelerated vascular calcification, as well as calciphylaxis in extreme cases with a greater than $80 \%$ mortality at 2 years. ${ }^{4}$

Warfarin is also a recognised risk factor for warfarin-induced nephropathy, characterised by tubular obstruction by red cell casts following glomerular haemorrhage. ${ }^{20}$ However, this condition is also being recognised with other anticoagulants and is probably best termed as anticoagulant-induced nephropathy. ${ }^{20}$

\section{Direct oral anticoagulants}

As a result of fixed dosing, no need for routine laboratory monitoring, few drug interactions, at least equal efficacy to vitamin $\mathrm{K}$ antagonists and lower risks of bleeding, DOACs (dabigatran, apixaban, rivaroxaban and edoxaban) have become the oral anticoagulants of choice in several conditions, including $\mathrm{AF}$, in the general population and patients with mild to moderate 
Table 2. Pharmacological targets and UK licensed indications of oral anticoagulants

\begin{tabular}{|c|c|c|c|c|c|c|}
\hline \multirow{2}{*}{$\begin{array}{l}\text { Oral } \\
\text { anticoagulant }\end{array}$} & \multirow[t]{2}{*}{ Target } & \multirow[t]{2}{*}{ UK indications } & \multicolumn{4}{|c|}{ Dosing based on $\mathrm{CrCl}$ (mL/min) } \\
\hline & & & $\geq 50$ & $30-49$ & 15-29 & $<15$ or ESKD \\
\hline Warfarin & $\begin{array}{l}\text { Inhibitor of vitamin } \\
\text { K-dependent clotting } \\
\text { factors }\end{array}$ & $\begin{array}{l}\text { AF, prosthetic heart } \\
\text { valve, VTE, TIA }\end{array}$ & \multicolumn{4}{|c|}{ Monitor INR } \\
\hline Dabigatran & $\begin{array}{l}\text { Direct thrombin } \\
\text { inhibitor }\end{array}$ & VTE, AF & \multicolumn{2}{|c|}{$\begin{array}{l}150 \mathrm{mg} \text { twice daily ( } 110 \mathrm{mg} \text { twice } \\
\text { daily if } \geq 80 \text { years, or on verapamil, } \\
\text { or increased bleeding risk) }\end{array}$} & \multicolumn{2}{|c|}{ Not recommended } \\
\hline Rivaroxaban & $\begin{array}{l}\text { Direct inhibitor of } \\
\text { activated factor } X\end{array}$ & $\begin{array}{l}\text { VTE, AF, or } \\
\text { atheroembolic } \\
\text { prophylaxis after ACS, or } \\
\text { in CAD, or PAD }\end{array}$ & 20 mg once daily & $\begin{array}{l}15 \text { mg once } \\
\text { daily }\end{array}$ & \multicolumn{2}{|c|}{ Not recommended } \\
\hline Apixaban & $\begin{array}{l}\text { Direct inhibitor of } \\
\text { activated factor } X\end{array}$ & VTE, AF & \multicolumn{2}{|c|}{$\begin{array}{l}5 \mathrm{mg} \text { twice daily ( } 2.5 \mathrm{mg} \text { twice daily if } \\
\text { two out of age } \geq 80 \text { years, Wt }<60 \mathrm{~kg} \\
\text { and } \mathrm{s} C r \geq 133 \mu \mathrm{mol} / \mathrm{L} \text { ) }\end{array}$} & $\begin{array}{l}2.5 \mathrm{mg} \\
\text { twice } \\
\text { daily }\end{array}$ & $\begin{array}{l}\text { Not } \\
\text { recommended }\end{array}$ \\
\hline Edoxaban & $\begin{array}{l}\text { Direct inhibitor of } \\
\text { activated factor } X\end{array}$ & VTE, AF & $\begin{array}{l}60 \mathrm{mg} \text { once daily } \\
\text { ( } 30 \mathrm{mg} \text { once } \\
\text { daily if } \mathrm{Wt}<60 \\
\mathrm{~kg} \text { and treatment } \\
\text { with verapamil, } \\
\text { dronedarone or } \\
\text { quinidine) }\end{array}$ & \multicolumn{2}{|c|}{30 mg once daily } & $\begin{array}{l}\text { Not } \\
\text { recommended }\end{array}$ \\
\hline
\end{tabular}

The dose adjustments suggested are for guidance only and the reader is directed to local protocols and formularies for definitive dosing. ACS = acute coronary syndrome; $\mathrm{AF}=$ atrial fibrillation; $\mathrm{CAD}=$ coronary artery disease; $\mathrm{CrCL}=$ creatinine clearance rate; $\mathrm{INR}=$ international normalised ratio; $\mathrm{PAD}=$ peripheral arterial disease; $\mathrm{s} C \mathrm{r}=$ serum creatinine; $\mathrm{TIA}=$ transient ischaemic attack; $\mathrm{VTE}=$ venous thromboembolism; $\mathrm{Wt}=$ body weight.

CKD. ${ }^{3,4,7,21}$ However, all DOACs have an element of renal excretion. Although patients with advanced CKD/ESKD have been generally excluded from the large DOAC clinical trials, ${ }^{3}$ on the basis of pharmacological modelling, rivaroxaban, apixaban and edoxaban have been approved for use in Europe for patients with severe CKD (Table 2). In the USA, apixaban has been licensed for use in patients with ESKD with, so far, encouraging results from observational studies. ${ }^{22}$ Ongoing clinical trials in patients with ESKD may help shed some clarity on these issues.

\section{Reversal of oral anticoagulants}

The anticoagulant effects of warfarin and direct factor Xa inhibitors can be attenuated and reversed using fresh-frozen plasma, prothrombin complex concentrate or recombinant factor VIIa. Vitamin K reverses the antithrombotic effects of warfarin, although large doses may result in sustained warfarin resistance. In contrast to other NOACs, dabigatran is removable via haemodialysis, and the monoclonal antibody idarucizumab is now available for instances where rapid reversal of dabigitran is needed. ${ }^{3}$ Andexanet alfa, a novel recombinant inactive form of factor $X a$, is available to reverse anticoagulation with rivaroxaban and apixaban. ${ }^{3}$

\section{Conclusion}

The decision on whether to anticoagulate patients with moderate or severe CKD, and especially those with ESKD is always complex with increased risks of bleeding and some doubts as to efficacy. To a large extent this has been driven by the systematic exclusion of these patients from large clinical trials. It is unlikely that solid evidence from clinical trials will be available to guide decision making in the near future, but such evidence is much needed. In this situation, a solid understanding of the condition in question and the available treatments is required to make an informed judgement call. An in-depth appreciation of the advantages and disadvantages of the currently available anticoagulants is a key element in the decision-making process.

\section{References}

1 Moody WE, Chue CD, Inston NG et al. Understanding the effects of chronic kidney disease on cardiovascular risk: are there lessons to be learnt from healthy kidney donors? J Hum Hypertens 2012;26:141-8.

2 Molnar AO, Bota SE, McArthur E et al. Risk and complications of venous thromboembolism in dialysis patients. Nephrol Dial Transplant 2018;33:874-80.

3 Potpara TS, Ferro C], Lip GYH. Use of oral anticoagulants in patients with atrial fibrillation and renal dysfunction. Nat Rev Nephrol 2018;14:337-51.

$4 \mathrm{Ng} \mathrm{KP}$, Edwards NC, Lip GY, Townend JN, Ferro C]. Atrial fibrillation in CKD: balancing the risks and benefits of anticoagulation. Am J Kidney Dis 2013;62:615-32.

5 Hughes S, Szeki I, Nash M], Thachil J. Anticoagulation in chronic kidney disease patients-the practical aspects. Clin Kidney J 2014:7:442-9.

6 Lutz J, Menke J, Sollinger D, Schinzel H, Thurmel K. Haemostasis in chronic kidney disease. Nephrol Dial Transplant 2014;29:29-40.

7 Kalra PA, Burlacu A, Ferro C], Covic A. Which anticoagulants should be used for stroke prevention in non-valvular atrial fibrillation and severe chronic kidney disease? Curr Opin Nephrol Hypertens 2018;27:420-5. 
8 Jain N, Reilly RF. Clinical Pharmacology of oral anticoagulants in patients with kidney disease. Clin J Am Soc Nephrol 2019:14:278-87.

9 Kundu S. Central venous disease in hemodialysis patients: prevalence, etiology and treatment. J Vasc Access 2010;11:1-7.

10 Gordon-Cappitelli ], Choi MJ. Prophylactic anticoagulation in adult patients with nephrotic syndrome. Clin J Am Soc Nephrol 2020;15:123-5.

11 Pavord S, Myers B. Bleeding and thrombotic complications of kidney disease. Blood Rev 2011;25:271-8.

12 Lau YC, Xiong Q, Lip GY, Blann AD. Effect of renal function on whole blood and fibrin clot formation in atrial fibrillation patients on warfarin. Ann Med 2016:48:275-81.

13 Davenport A. What are the anticoagulation options for intermittent hemodialysis? Nat Rev Nephrol 2011;7:499-508.

$14 \mathrm{Ng} \mathrm{KP}$, Townend JN, Ferro C]. Randomised-controlled trials in chronic kidney disease-a call to arms! Int J Clin Pract 2012;66:913-5.

15 Ocak G, Ramspek C, Rookmaaker MB et al. Performance of bleeding risk scores in dialysis patients. Nephrol Dial Transplant 2019;34:1223-31

16 Aursulesei V, Costache, II. Anticoagulation in chronic kidney disease: from guidelines to clinical practice. Clin Cardiol 2019;42:774-82.

17 Arepally GM. Heparin-induced thrombocytopenia. Blood 2017:129:2864-72.
18 Sun Z, Lan X, Li S, Zhao H, Tang Z, Xi Y. Comparisons of argatroban to lepirudin and bivalirudin in the treatment of heparin-induced thrombocytopenia: a systematic review and meta-analysis. Int ] Hematol 2017;106:476-83

19 Wilde MI, Markham A. Danaparoid. A review of its pharmacology and clinical use in the management of heparin-induced thrombocytopenia. Drugs 1997;54:903-24.

20 Glassock RJ. Anticoagulant-Related nephropathy: It's the real McCoy. Clin J Am Soc Nephrol 2019;14:935-7.

21 Kumar S, Lim E, Covic A et al. Anticoagulation in concomitant chronic kidney disease and atrial fibrillation: JACC review topic of the week. J Am Coll Cardiol 2019;74:2204-15.

22 Siontis KC, Zhang X, Eckard A et al. Outcomes associated with apixaban use in patients with end-stage kidney disease and atrial fibrillation in the United States. Circulation 2018;138:1519-29.

Address for correspondence: Prof Charles J Ferro, Department of Nephrology, Queen Elizabeth Hospital, Birmingham B15 2WB, UK.

Email: charles.ferro@uhb.nhs.uk

\section{Royal College Q. of Physicians

\section{Acute care toolkit 15: Managing acute care problems in pregnancy}

Pregnant women can present to any acute hospital service at any time during their pregnancy or the postpartum period, up to 12 months post-delivery. Women may present with acute medical problems that need to be managed differently because of pregnancy, or may present with obstetric syndromes.

This toolkit provides practical guidance on managing women with acute medical problems in pregnancy. It also advises healthcare staff to take the opportunity to ask about a woman's mental wellbeing when she comes to hospital for other reasons during or after pregnancy; women with a history of mental health problems are more likely to develop new symptoms during pregnancy and postpartum.

Essential reading for front-line NHS staff who may be unfamiliar with the normal physiology of pregnancy and/or diseases that present in pregnancy.

Download now at: www.rcplondon.ac.uk/act15
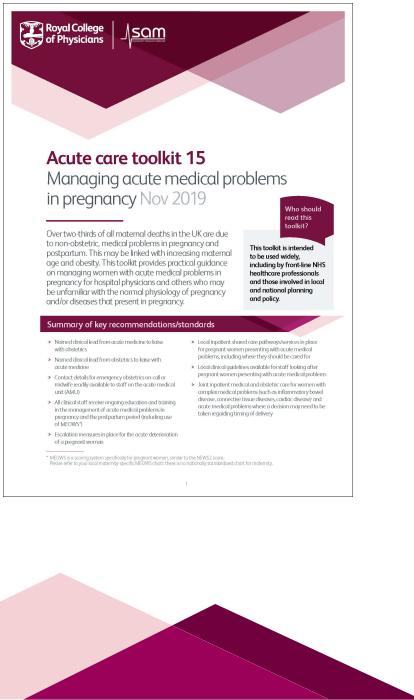